\title{
Air-conditioning guidelines for healthcare facilities during the covid pandemic
}

\author{
Sharma A. ${ }^{1}$, Kumar K R. ${ }^{2}$, K Patnaik S. ${ }^{3 *}$ \\ DOI: https://doi.org/10.17511/ijmrr.2021.i02.10
}

\footnotetext{
${ }^{1}$ Ashutosh Sharma, MBBS MD, Professor, Department of Hospital Administration, Armed Forces Medical College, Pune, Maharastra, India.

2 Ramesh Kumar K, MBBS, Resident, Department of Hospital Administration, Armed Forces Medical College, Pune, Maharastra, India.

3* Saroj K Patnaik, MBBS, MHA, Professor, Department of Hospital Administration, Armed Forces Medical College, Pune, Maharashtra, India.
}

Coronavirus disease (COVID-19) is an infectious disease caused by a newly discovered Severe Acute Respiratory Syndrome Coronavirus 2 (SARS-CoV-2). The disease spreads primarily through respiratory droplets, physical contact and contact with surfaces as well as fomites. Isolation of patients in hospitals and quarantine of contacts in separate facilities are the mainstay of outbreak containment. This pandemic has brought forward various challenges to the hospital administrators, one of the most important being air-conditioning of hospitals in the time of this pandemic. Paradox to the positive pressure rooms required for critically ill and vulnerable patients, it is negative pressure rooms that are required to contain and avoid the spread of COVID19. This descriptive study provides consolidated guidelines to establish or retrofit the available air-conditioning system at hospitals, at the time of the COVID pandemic.

Keywords: Air-conditioning, COVID-19, Isolation rooms, Negative pressure

Corresponding Author

Saroj K Patnaik, MBBS, MHA, Professor, Department of Hospital Administration, Armed Forces Medical College, Pune, Maharashtra, India.

Email: patnaik.saroj@gmail.com
How to Cite this Article

Sharma A, Kumar KR, Patnaik SK. Air-conditioning guidelines for healthcare facilities during the covid pandemic. Int J Med Res Rev. 2021;9(2):109-114. Available From

https://ijmrr.medresearch.in/index.php/ijmrr/article/ view/1273
To Browse

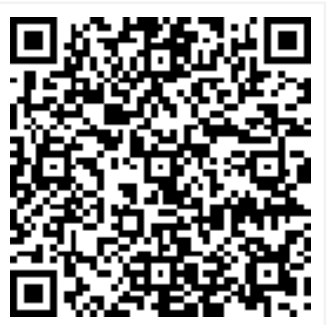

Manuscript Received 2021-03-25

Conflict of Interest No

Review Round 1
2021-03-27
Funding
Nil

Condil (C) 2021 by Ashutosh Sharma, Ramesh Kumar K, Saroj K Patnaik and Published by Siddharth Health Research and Social
Welfare Society. This is an Open Access article licensed under a Creative Commons Attribution 4.0 International License https://creativecommons.org/licenses/by/4.0/ unported [CC BY 4.0].

\section{Review Round 3}

Review Round 2

2021-04-07

Ethical Approval

Yes
Accepted 2021-04-29

Note 


\section{Introduction}

Various infectious diseases like SARS in 2003, Swine flu in 2009, MERS in 2012 and recently SARS-CoV-2 have challenged the health care providers across the globe. Quarantine and Isolation are an important mainstay of cluster containment. These measures help by breaking the chain of transmission in the community [1]. Several models of disease causation have been proposed. Among the simplest of these is the epidemiologic triad or triangle, the traditional model for infectious disease. The triad consists of an external agent, a susceptible host, and an environment that brings the host and agent together. In this model, the disease results from the interaction between the agent and the susceptible host in an environment that supports transmission of the agent from a source to that host [2]. Whereas the hospital may not have such control over the host factors and agents, the hospital certainly is responsible for the environment that surrounds the patients [3]. Controlling the environment is one of the major factors in handling any such crisis which plays a vital role in breaking the chain of transmission of infection. Air-conditioning and ventilation are such important environmental control measures, especially in the hospital area, which help in prevention and control over the infection. Healthcare facilities, both public and private are being prepared to take on this challenge of the COVID 19 Pandemic. Hence it is critical for hospitals to foresee the administrative issues to address the pandemic. Although the entire hospital has to be ready up to handle COVID patients, some areas have to be specifically geared for the purpose. These include the Flu Clinics for initial screening of suspected COVID cases, establishing Isolation Wards for confirmed COVID patients, as well as COVID ICUs/ HDUs for those who along with being positive is critically ill. Similarly, provision has to be made for the conduct of surgeries and deliveries of COVID positive patients. Besides this, the patient or his/ her specimen may be carried to different parts of the hospital for investigation or intervention, for which the general principles of awareness, patient masks, standard precautions including appropriate PPE and hand hygiene have to be followed.

\section{Need of Environmental Control}

The basic differences between air-conditioning for hospitals and other building types stem from the following characteristics(4): -
01. Need to restrict air movement in and between departments.

02. Specific requirements for ventilation and filtration to dilute and remove contamination (odour, airborne microorganisms and viruses, hazardous chemicals and radioactive substances).

03. Different temperature and humidity requirements for various areas.

04. Design sophistication needed for accurate control of environmental conditions.

Air-conditioning in hospitals, besides providing comfort to patients and staff, is essential to control infection. As a result, many wards and departments (especially operating department, ICUs) in most hospitals are air-conditioned. The extent of airconditioning in various hospitals is dependent on the location of the hospital, building design, and the type of patients the hospital handles. The management of COVID patients in hospitals has brought up additional challenges, where, on one side air-conditioning is necessary for comfort and climate control but its usage increases the risk of spread of coronavirus to other parts of the hospital through the air-conditioning system. Hence specific modification by retrofitting and other structural modification is required for making these hospitals safe not only for patients but also for the health care providers and other clientele. Since most of the hospitals handling COVID patients would already have the infrastructure including air-conditioning, the present study primarily deals with retrofitting the air-conditioning systems to provide a safe environment. Where new constructions are undertaken the principles should be incorporated, to make the facility future-ready.

\section{Infrastructural Recommendations}

The planning parameters for air-conditioning stems from the premise that air-conditioned facilities in any infectious disease/ COVID hospitals should have no recirculation of air from patient care areas, have higher air changes to dilute the contaminants and pressure lower than surrounding areas to contain the infection. The time required for removing a given percentage of airborne particles from a room or space depends on the number of air changes per hour $(\mathrm{ACH})$, location of the ventilation inlet and outlet, and the physical configuration of the room or space. 
The scope of this document will be to provide safe ventilation for Flu Clinics, Isolation Wards, ICUs/ HDUs, and Operating Theatres.

\section{(A) Flu Clinic.}

It is the designated screening area for COVID-19 suspected cases, where the patient stays for a short time but the medical staff has to stay for an entire shift. Since the area has moderate risk and low occupancy, the primary aim of ventilation is dilution and removal of contaminants. Hence the Clinic should be established in a non-AC room, which has an adequate circulation of air $\&$ an effective exhaust system. If air-conditioning is required because of inclement weather, the room should be provided with a separate AC, preferably a split airconditioner. The room should also have an effective exhaust system through windows and or exhaust fans.

\section{(B) Isolation Ward.}

The ward houses COVID positive patients with mild or moderate symptoms. Since the area has moderate risk and continued occupancy, the aim of ventilation are environment comfort, removal of contaminants, non-turbulent unidirectional airflow and prevention of leak of contaminated air to surrounding non-infected areas. Where the wards are not air-conditioned, installing an adequate number of exhaust fans may create dilution and removal of contaminated air, increased unidirectional airflow and negative pressure. However, it is to be ensured that the exhaust fans should not throw the exhausted air near an occupied building, public place or intake of airconditioning plants.

In centrally air-conditioned areas, dedicated Air Handling Units (AHU) should supply air to Isolation wards. Since the droplet nuclei and viral particle may pass through the microfilters, the room air should not be recirculated and $100 \%$ fresh air should be pumped in. Blocking of return air vents may be implemented as an immediate measure before accommodating COVID positive patients. The dampers of the system should be adjusted to ensure that there is no recirculation of air and the outflow of air should be greater than the inflow, to maintain a negative pressure in the ward. The ward should have 12 air changes/ hour, the temperature should be maintained between $240 \pm 20 \mathrm{C} \&$ relative humidity at $40-60 \%$ [5].
The exhausted air should be let off into the atmosphere through an upward plume at a height of $3 \mathrm{~m}$ above the tallest point of the building and at least be 25 feet away from air intakes or nearest inhabited areas [5].

Inwards having multiple split or window ACs, exhaust fans should be fitted to remove contaminated air and to maintain negative pressure concerning adjacent spaces. Doors and windows connecting to other rooms or corridors should be self-closing \& sealed, to prevent leakage of contaminated air. Where possible, an anteroom should be established to moderate the pressure change while opening doors.

\section{(C) Isolation ICUs/ HDUs.}

The ICUs/ HDUs house critically or severely ill COVID positive patients. The area has a high risk of infection due to the conduct of many aerosolgenerating procedures and continued occupancy, both of the patients and staff. Hence the staff are in full PPE. Here the aims of ventilation are environment comfort, removal of contaminants, negative pressure and prevention of leak of contaminated air to surrounding non-infected areas. Nearly all ICUs would have centralized airconditioning, either from the central plant or from a dedicated compact unit.

Ideally, isolation ICUs/ HDUs should be established as single occupancy hermetically sealed rooms with dedicated air-conditioning. In a centrally airconditioned facility the Air Handling Units should supply $100 \%$ fresh air and the dampers of the system should be adjusted to ensure that there is no recirculation of air. Blocking of return air vents may be implemented as an immediate measure before accommodating COVID positive patients.

Automatic or motorized dampers and manometers, which regulate pressures at the air intake and exhaust outlets, should be installed. To maintain consistent offset airflow, the difference between exhaust and supply should create a pressure differential of about 0.01 -inch water gauge or 2.5 Pascals [4]. All rooms should have a permanently installed device [Fig-1] and/or mechanism to constantly monitor the differential air pressure between the ICU and the corridor or adjacent spaces of the room.

A local visual means shall be provided to indicate whenever negative differential pressure is being maintained. 
Negative pressure in this system is to prevent leakage of contaminated air from ICUs into surrounding areas.

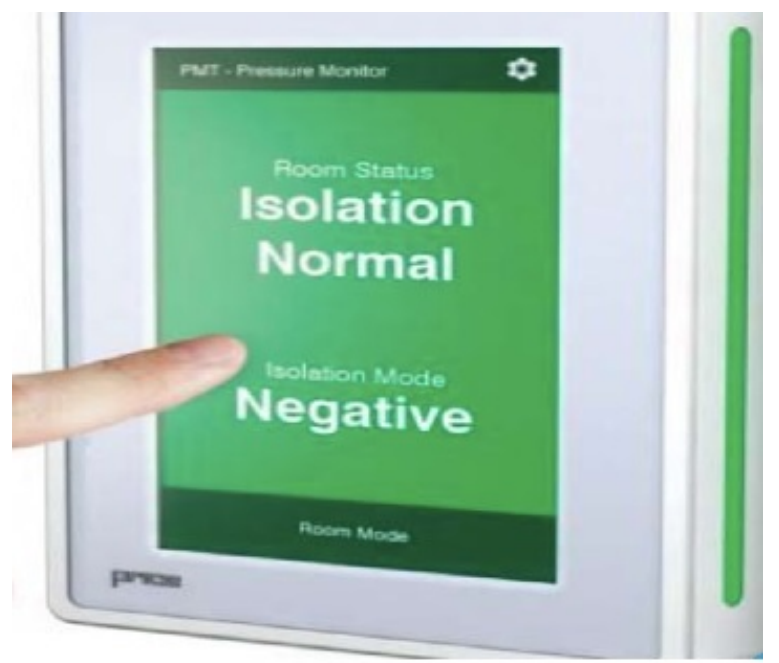

FIGURE 1 : Visual Monitors

Doors and windows connecting to other rooms or corridors should be self-closing \& sealed, to prevent leakage of contaminated air. An anteroom should always be established at the entrance to ICU to moderate the pressure change while opening doors. The area can also be used for donning of PPE and for documentation. The ICU should have 12 air changes/ hour supplied through a non-aspirating diffuser with the temperature and relative humidity to be maintained between $22-24 \circ \mathrm{C}$ and $40-60 \%$ respectively [5].

The exhausted air should be let off into the atmosphere through an upward plume at a height of $3 \mathrm{~m}$ above the tallest point of the building and at least be 25 feet away from air intakes or nearest inhabited areas [FIG-2] [5, 6]. In the hospital where this is not possible, 'exhaust air treatment' modalities should be built. The common 'exhaust air treatment' modality available is HEPA filtration of exhausted air [4-8].

Alternatively, exhausted air could be passed through chemical disinfection by using a diffused air aerator tank (non-metallic) containing 1\% sodium hypochlorite solution or passing through a heated duct of more than $1000 \mathrm{C}$ temperature for at least 3 seconds. Other modalities of 'exhaust air treatment' mentioned in literature are UV irradiation (254 nm) with an exposure time of $15 \mathrm{~min}[6,9-12]$.

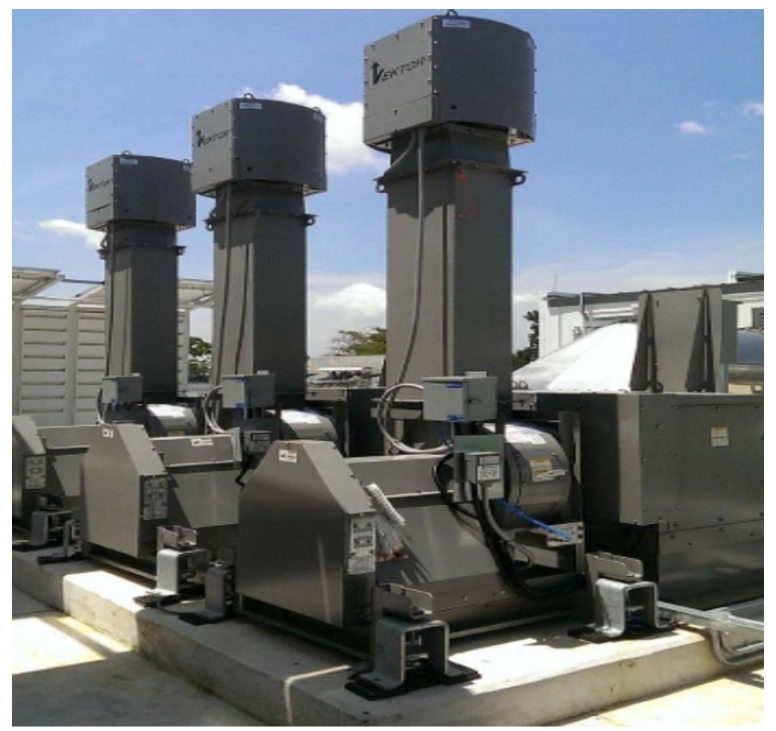

FIGURE 2 : Exhaust Stacks on Rooftop

Where it is not possible to centrally control the negative pressure differential between the ICU and other areas, multiple exhaust fans should be fitted to remove contaminated air and to maintain negative pressure in the ICU. Where an ICU facility to handle COVID patients is being created, it is desirable to have hermetically sealed individual rooms, a dedicated AC plant with centralized sensor-based automatic control of pressure differentials in rooms and controlled exhaust through HEPA filters into a safe environment.

\section{(D) Isolation ORs/ OTs.}

Hospitals should earmark one or two OTs for surgeries on confirmed or suspected COVID positive patients. These should preferably be close to other COVID facilities and separate from the main operating department. In a centrally air-conditioned facility the Air Handling Units should supply $100 \%$ fresh air and the dampers of the system should be adjusted to ensure that there is no recirculation of air. Blocking of return air vents may be implemented as an immediate measure before accommodating COVID positive patients.

Automatic or motorized dampers and manometers, which regulate pressures at the air intake and exhaust outlets, should be installed. The OT should be maintained at a negative pressure of 5 Pascals to prevent leakage of contaminated air from OTs into surrounding areas [13]. Doors should be self-closing $\&$ hermetically sealed [7]. 
The OT should have 15-20 air changes/ hour supplied through a non-aspirating diffuser with the temperature maintained between $22 \pm 20 \mathrm{C}$ and relative humidity between $40-60 \%$ [5]. (i) The exhausted air should be let off into the atmosphere through an upward plume at a height of $3 \mathrm{~m}$ above the tallest point of the building and at least be 25 feet away from air intakes or nearest inhabited areas $[5,6]$. Where this is not possible exhaust air should be treated through HEPA filtration or chemically disinfected by passing through $1 \%$ sodium hypochlorite solution or a heated duct of more than $1000 \mathrm{C}$ temperature for at least 3 seconds [6, 9-12].

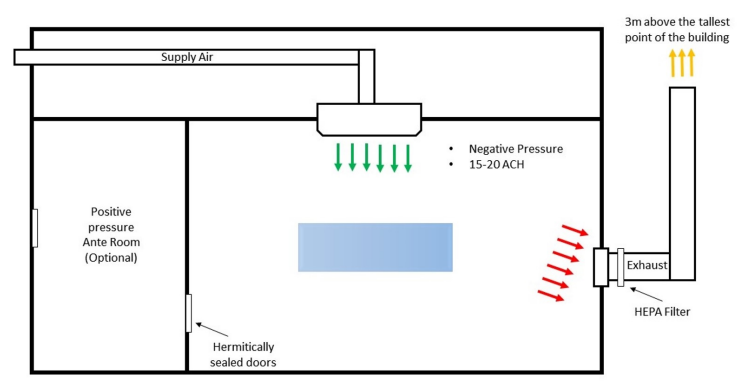

FIGURE 3 : Layout of OT

\section{Conclusion}

Air conditioning is an essential component of HVAC system in most modern hospitals for patient and staff comfort, as well as infection control. However, in an environment of airborne infection like COVID, the air-conditioning system can itself spread the disease if not suitably controlled. The aim of airconditioning in COVID facility should be to provide comfort for patients and staff, rapid removal of infection carrying particles, prevent recirculation of air, maintain a negative pressure from surroundings, and ensure safe disposal of exhaust air.

\section{Negative pressure room Checklist}

CHECKLIST FOR MONITORING NEGATIVE PRESSURE ROOMS Verify the room sensors are calibrated and working properly Ensure room controllers and monitors are working and communicating with supply and exhaust airflow valves

Verify the room is operating at a negative pressure relative to surrounding areas and ensure room pressure is being properly documented Verify correct air changes per hour

Confirm temperature and humidity ranges are in the room

Verify room air is being exhausted directly outside through a HEPA filter Ensure doors are being kept closed except during healthcare personnel entry/exit
Confirm patient rooms are visible on your building automation system, for prompt notification of any issues

Consider updating older supply and exhaust VAV boxes to fast-acting Venturi air valve or measure airflow valve

Plan for an influx of patients and how to address isolation requirements in your facility

\section{Reference}

01. NCDC, MoHFW G. COVID -19 Outbreak Guidelines for Setting up. 2020.

[Crossref]

02. Principles of Epidemiology in Public Health Practice. Concepts of Disease Occurrence, Third edition. 2012;1-52.

[Crossref]

03. Rao S. Designing Hospital for better Infection Control- an Experience. Med J Armed Forces India. 2004 Jan;60(1)63-6.

doi: $10.1016 /$ S0377-1237(04)80163-1 [Crossref]

04. 2019 ASHRAE Handbook-HVAC Applications (SI). ASHRAE Handbook-HVAC Appl. $2019 ; 108(10)$.

[Crossref]

05. ASHRAE, ANSI. "ANSI/ASHRAE/ASHE Standard 170-2013, Ventilation of Health Care Facilities. " American Society of Heating, Refrigerating and Air-Conditioning Engineers, Inc, Atlanta. 2013. [Crossref]

06. ISHRAE. COVID-19 Guidance Document for Air Conditioning and Ventilation. 2020.

[Crossref]

07. IHFG. Isolation Rooms - Guideline Section International Health Facility Guidelines. 2017;19-28.

Available from: [Article] [Crossref]

08. WHO. Severe Acute Respiratory Infections Treatment Centre D4. 2020(January)1-50. [Crossref]

09. World Health Organization. Guidance on regulations for the Transport of Infectious Substances the Transport of Infectious Substances. 2008(January 2007)1-56.

Available from: [Article] [Crossref] 
10. ECDC. Disinfection of environments in healthcare and non- healthcare settings potentially contaminated with Target audience Cleaning options for healthcare settings after the management of a suspected or confirmed case of COVID-19. Eur Cent Dis Prev Control. 2020.

[Crossref]

11. MoFHW, GoI 10Apr20. COVID-19- Guidelines on disinfection of common public places including offices. $2019 ; 1-11$.

[Crossref]
12. Darnell ME, Subbarao K, Feinstone SM, Taylor DR. Inactivation of the coronavirus that induces severe acute respiratory syndrome, SARS-CoV. J Virol Methods. 2004 Oct;121(1)85-91.

doi: $10.1016 / j . j v i r o m e t .2004 .06 .006 \quad$ [Crossref]

13. Malhotra N, Bajwa SJS, Joshi M, Mehdiratta L, Trikha A. COVID Operation Theatre- Advisory and Position Statement of Indian Society of Anaesthesiologists (ISA National). Indian J Anaesth. 2020 May;64(5)355-362.

doi: 10.4103/ija.IJA_454_20 [Crossref] 